\title{
DE OLHO NA WEB...
}

\section{Elza M aria Ferraz B arboza}

IBICT - Coordenação de Inovação/Divisão de Prospecção Tecnológica <elza@ibict.br>

A W ebéuma mídia prática, rápida eideal para a divulgação das atividades técnico-científicas desenvolvidas individualmente ou em parceria com outras instituições de pesquisa. Essa divulgação se dá não só por meio de sites pessoais mas também através de sites institucionais. São sites criativos e sobretudo informacionais que atendem às necessidades de informação de profissionais, estudantese professores, assim como estimulam nas novas gerações a curiosidade e 0 gosto pelas descobertas científicas e tecnológicas, incentivando a formação de novos cientistas.

De 0 lho na W eb... apresenta neste número, sites de instituições governamentais que promovem 0 avanço brasileiro nas áreas de física; ciências humanas (antropologia, arqueologia e lingüística), botânica, zoologia, ciências da terra; ciências espaciais e capacitação e fomento de atividades de nível superior.

\section{CBPF}

$<$ http://www.cbpf.br>

24/11/2000

Centro Brasileiro de Pesquisa em Física (CBPF)

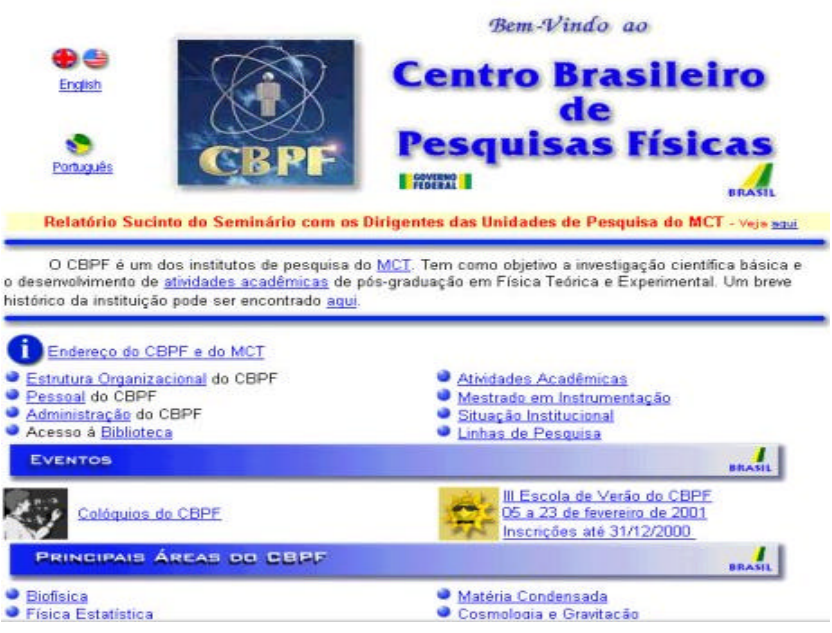

0 CBPF é um centro de referência em física. Seu site, em versão também em inglês, divulga suas atividades de pesquisa científica básica nas áreas de biofísica, física estatística, teoria dos campos, física de al tas energias, física nuclear e raios cósmicos, moléculas e superfície, instrumentação científica, matéria condensada, cosmologia e gravitação, e de seu Laboratório de Cosmologia e Física Experimental de A Itas Energias (Lafex) que trabalha com colaboração de pesquisadores e laboratórios internacionais como o Fermilab (Fermi $\mathrm{N}$ ational A ccelerator Laboratory < http:ll www.fnal.gov>) e o Cern (European Laboratory for Particle Physics < http://cern.web.cern.ch>), tendo como principal objetivo a formação de recursos humanos. Divulga suas atividades acadêmicas em física teórica e experimental informando sobre seus cursos de pósgraduação (mestrado e doutorado) e seus programas.

A informação dentro do site está estruturada em quatro blocos: 1) informações institucionais, biblioteca, atividades acadêmicas, avaliação institucional e internacional; 2) eventos; 3) áreas de atuação e 4) outros na Internet (lista de servidores de física no Brasil e no exterior, links de acesso a sociedades de física e agências espaciais internacionais, banco de pre-prints (Brasil)etc. 0 ferece links para serviços nos buscadores genéricos A ItaV ista e Cadê?, e para acesso a jornais e livros eletrônicos da área. Por intermédio do link "Biblioteca" o usuário tem acesso à memória da produção técnicocientífica do CBPF, Biblioteca V irtual de Ó ptica Básica e A plicada, a home page do CNEN (dpx.cnen.gov.br) e biblioteca biográfica virtual "Leite Lopes". Também oferece mirrors para los A lamos e W eb of Science. 0 seu motor de busca oferece opções de buscas simples e avançada.

Inclui links para instituições como Scientific A merican (<http://www.sciam.com $>$ ), Exploratorium (<http:// www.exploratorium.edu $>)$, A merican Physical Society (<htt://www.aps.org>) e Centro Latino A mericano de Física (CLA F) entre outras, eainda para 150 universidades americanas.

Seu ponto forte é ser 0 único site brasileiro que divulga informações de nível nacional e internacional voltadas para a área de física, sendo imprescindível para pesquisadores, professores e estudantes que desejam desenvolver e acompanhar as pesquisas realizadas na área. Contém links para instituições e Sociedade de Física do Brasil, para a plataforma Lattes, sendo também um portal para centros internacionais congêneres. 


\section{MPEG}

$<$ http://www.museu-goeldi.br $>$

24/11/2000-11-24

M useu Paraense Emílio G oeldi (M PEG)

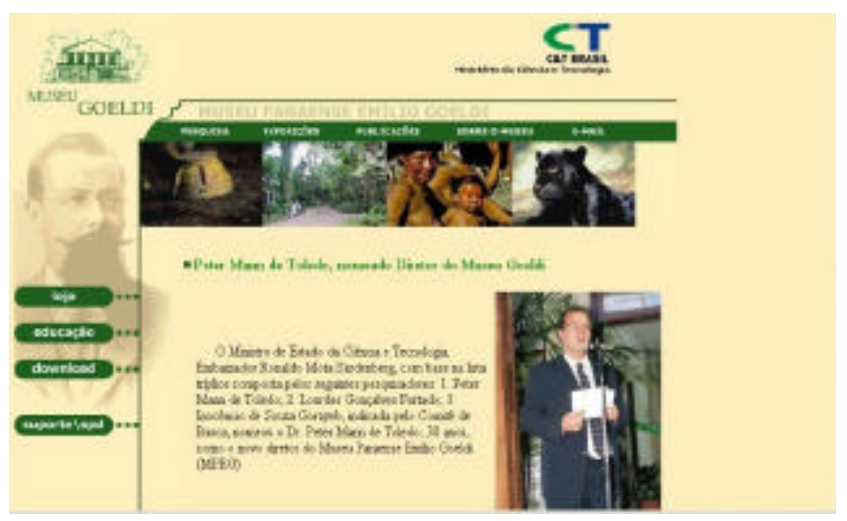

Divulga informações sobre suas atividades científicas desenvolvidas nas áreas de antropologia, arqueologia, lingüística, botânica, zoologia e ciências da terra. 0 M useu é um inventário dos recursos naturais da A mazônia com relação à sua flora , fauna, o homem e seu ambiente físico. A través de sua U nidade de A nálises Espaciais faz sensoreamento remoto da região. A tua também na área de formação de recursos humanos, oferecendo cursos de pós-graduação em biologia em convênio com a Universidade do Pará, e cursos de mestrado e doutorado com o objetivo de capacitar e formar biólogos e zoólogos ambientais na Região A mazônica.

A s suas coleções, na maior parte iniciadas no século XIX, estão organizadas nas quatro grandes áreas cobertas pelo museu. $\mathrm{O}$ Departamento de Ciências $\mathbf{H}$ umanas mantém coleções de arqueologia, etnografia e lingüística, encontrando-se registradas as línguas amazônicas documentadas em fitas e vídeos. 0 museu utiliza também exposições, a biblioteca e uma coleção didática para divulgar os resultados de suas pesquisas. 0 D epartamento de Botânica éresponsável pelo herbário João M urça Pires, xiloteca, palinoteca e histoteca que é especializada em material botânico da A mazônia. 0 Departamento de Ciências da Terra abriga a coleção de paleontologia que está dividida em três acervos: paleovertebrados, paleoinvertebrados, paleobotânica. A coleção de minerais/ rochas é formada por peças das espécies mineralógicas e litológicas representativas da geologia amazônica, dando ênfase ao registro das riquezas minerais do estado do Pará. U m acervo osteológico foi criado recentemente com 0 objetivo de apoiar o acervo de paleovertebrados nos estudos comparativos entre as faunas atual e passada. No Departamento de Zoologia estão as coleções de herpetologia (repteis e anfíbios), de ornitologia, de mastozoologia, de invertebrados. São mantidas as coleções de valor histórico de A dolfo Ducke, Roger A rlé e dos Bechyné, além de um acervo de ictiologia. No entanto, a visualização das peças dessa rica e ímpar coleção não é disponibilizada pelo site.

Inclui link para acesso à lista de suas publicações com instrução para aquisição de exemplares,disponibilizando seus arquivos em formato $A$ dobe $A$ crobat (PDF).

É um museu de renome internacional tanto pelo nível acadêmico de suas pesquisa quanto por ser único no gênero voltado para registrar as riquezas da A mazônia.

É um sitepara ser visitado por pesquisadores, especialistas, estudantes de todos os níveis acadêmicos e também do ensino fundamental.

\section{IN PE}

$<$ http://www.inpe.br>

27/11/2000-11-27

Instituto $\mathrm{N}$ acional de Pesquisas Espaciais (IN PE)

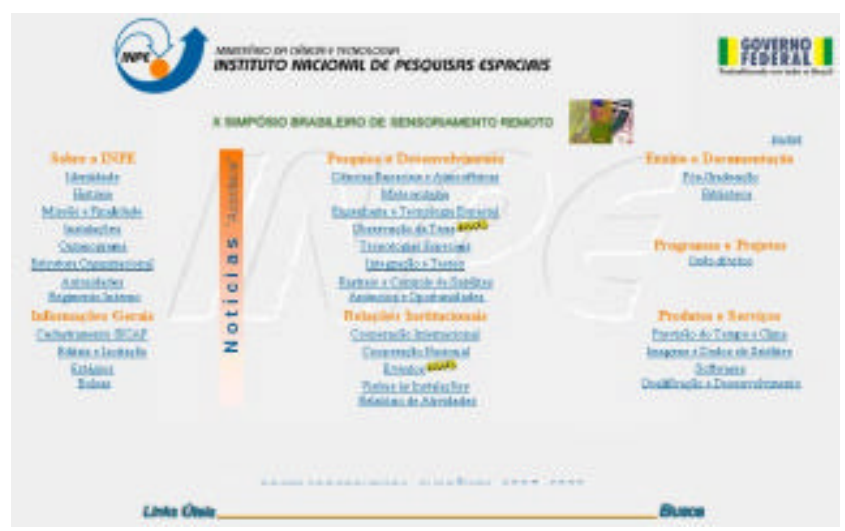

0 site divulga as atividades desenvolvidas pelo Inpe nas áreas de ciência espaciais e atmosféricas, meteorologia, engenharia e tecnologia espacial, observação da terra, rastreio e controle de satélites. A instituição coordena, estimula e apóia os trabal hos e estudos relacionados ao espaço, a formação de pesquisadores capacitados para desenvolver projetos de pesquisas espaciais e o estabelecimento da cooperação com outros países. É o principal órgão de execução civil para o desenvolvimento de pesquisas espaciais.

0 conteúdo do site está estruturado em sete blocos: informações sobre o Inpe, onde 0 internauta encontra informações gerais, pesquisas em desenvolvimento, produtos e serviços, programas e projetos, relações institucionais, ensino e documentação sobre a instituição. 
A través de sua biblioteca dá apoio à pesquisa e aos cursos de pós-graduação disponibilizando seu acervo, servindo de portal para buscadores genéricos tais como o Yahoo!, A ItaV ista, Lycos, InfoSeek, Cadê? e A chei!! e parasites de instituições como U SP, IT A, U nicamp, Rebae etc.

O ferece também revistas eletrônicas com texto completo e para consultar seu acervo bibliográfico (artigos, relatórios técnicos etc.) é só acessar 0 endereço $<\underline{h t t p: / /}$ www.sirius.sir.inpe.br/sirius.> (Internet Explorer 4.x ou superior).

Seus links remetem para instituições públicas, instituições de pesquisa, fundações e universidades no Brasil assim como para as principais agências espaciais internacionais com quem o Inpe mantém cooperação e contato permanente, tais como: a N asa (< http://www.nasa.gov/> ) e NOAA (The National O ceanic \& A tmospheric A dministration < http://www.noa.gov/>) dos Estados unidos, CNES (Centre N ational d'Etudes Spatiales < http://www.cnes.fr>) da França, DLR (D eustchen Zentrum für Luft und Raumfahrt> da A lemanha, ESA (European space A gency <http://www.esa.int/>) da Europa, CONAE (Comisión Nacional de A ctividades Espaciales < http://www.conae.gov.ar/> ) da A rgentina, CA ST (C hinese A cademy of Space T echnology < http:// www.cast.ac.cn > da C hina. M antém link para o web site oficial do governo brasileiro e outro que dá informações so bre o desflorestamento da A mazônia brasileira (1998-1999).

Inclui os serviços prestados pelo Inpe como: Previsão do T empo e do Dia dá informações, inclusive ilustradas com gráficos, a respeito da situação dosventos, da temperatura do mar, dos nevoeiros, etc.; o serviço de Imagens e $D$ ados de Satélites disponibiliza informações através de imagens sobre o tempo e o clima, geadas, nevoeiros, queimadas, EI $\mathrm{N}$ iño, La N iña etc., todas acompanhadas de gráficos.

Inclui links para o web site oficial do governo brasileiro, para o Programa Desflorestamento da A mazônia 19981999 e também para seus programas e projetos. É um portal para sites meteorológicos de países de todos os continentes.

Dá informações completas para aqueles interessados em ingressar nos seus cursos de pós-graduação (mestrado e doutorado) além de incluir notícas interessantes sobre as áreas de cobertura da instituição.

Informa sobre seus serviços de qualificação e desenvolvimento de produtos de alta tecnologia, e treinamento em áreas específicas. Seus serviços são utilizados por mais de 500 clientes externos das mais diversas áreas.

É um siteímpar, pleno de informações, que interessa não só a cientistas, professores, pesquisadores, estudantes, mas também ao cidadão comum interessado em se inteirar e se encantar com o desenvolvimento dos trabal hos voltados para o estudo do universo infinito.

\section{CAPES}

< http://capes.gov.br >

23/11/2000

Coordenação de A perfeiçoamento de Pessoal de Nível Superior

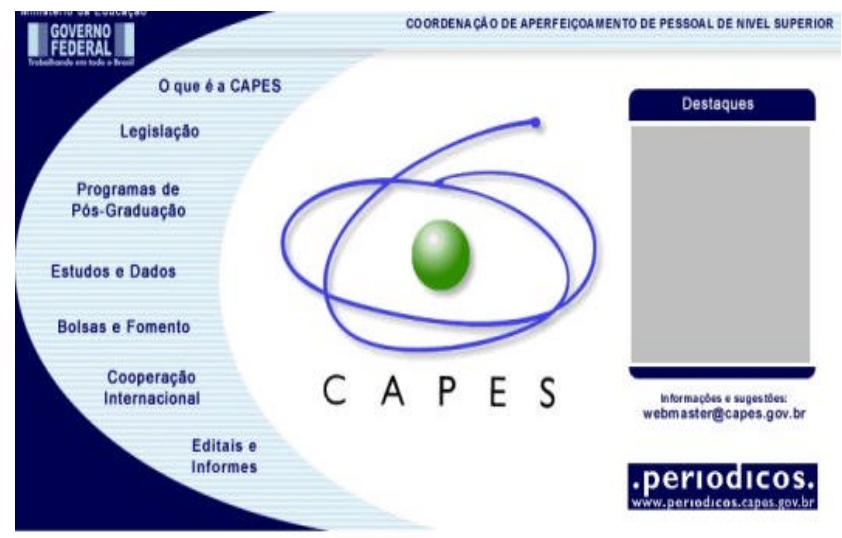

É um site de suma importância, servindo de ponto de referência para profissionaisdenível superior eacadêmicos que pretendem se aperfeiçoar em suas áreas de domínio, e pelo fato de ser uma instituição governamental que fomenta estudos e atividades que contribuam direta ou indiretamente para o desenvolvimento e consolidação das instituições de nível superior. A C apes através de seu site, divulga informações do desempenho de suas atividades que envolvem propostas de planos nacionais de pósgraduação, acompanhamento e coordenação de sua execução, avaliação periódica dos programas de pósgraduação e apreciação do mérito de solicitação de bolsas ou auxílios.

A informação está estruturada em oito links: 1) informações Institucionais tais como missão, objetivos, estrutura, orçamento, licitações; 2) aspectos da legislação da pós-graduação emanada do poder público com relação à validade dos diplomas obtidos no Brasil e no exterior, dos conceitos atribuidos pela agência nas avaliações dos programas, dos programas estrangeiros oferecidos no Brasil em convênios com instituições brasileiras, da avaliação de reconhecimento de cursos de pós-graduação lato-sensu (especialização, aperfeiçoamento), dos cursos de MBA e dos mestrados profissionais; 3) sistemática para 
implementação, avaliação e coleta de dados dos programas de pós-graduação; disponibiliza a lista dos programas de pós-graduação e seus conceitos, organizada por áreas e regiões geográficas, resultante da avaliação da Capes, e informa sobre a obtenção de bolsas de M estrado, de doutorado e de professor visitante. Divulga também informações sobre os programas de apoio ao desenvolvimento científico e tecnológico como o Padct III, Procad e M estrado Interinstitucional ; 4) estudos e dados da pós-graduação (Boletim Estatístico e publicações da A gência); 5) programas de caráter permanente que promovem a pós-graduação através do financiamento de bolsas de estudos e das atividades acadêmicas; 6 ) acordose iniciativas de cooperação com organismos internacionais e governos estrangeiros; 7 ) editais de programas para 0 atendimento de demandas com vistas à redução dos desequilíbrios e lacunas na pós-graduação brasileira e informes de interesse geral da comunidade acadêmica. 0 novo link .periódicos incorporado ao site é um portal (< http://www.periodicos.capes.gov.br $>$ ) que tem como objetivo facilitar e agilizar as pesquisas bibliográficas, permitindo 0 acesso a periódicos estrangeiros através de bases de dados referenciais. São títulosque cobrem asáreas de agronomia, biologia, ciência dos alimentos, economia, engenharia, geociências, letras, lingüística e sociologia. A lém das bases temáticas possibilita a consulta a um índice de patentes e à base geral e de referência e citações, o W eb of Science, ao mesmo tempo que disbonibiliza aproximadamente 1.400 títulos em texto completo com cobertura a partir de 1995.

Seus pontos fortes são deixar transparente para o cidadão todo o processo dasatividades desenvolvidas pela $C$ apese a clareza e objetividade oferecida por seus links, o que facilita a navegação, guiando o usuário à informação que ele necessita.

O público-alvo é toda a comunidade acadêmica , professores e alunos das instituições de ensino superior do país. 